\section{Minimum database} or massively debatable bloods? correlation of urea strip and external laboratory results, and their predictive value for renal disease in 768 dogs and cats

\section{David Mills}

PDSA Thamesmead Hospital, London, United Kingdom Royal Veterinary College, London, United Kingdom

\section{OBJECTIVES}

1. Assess the correlation of urea strips (USt) with external laboratory results (EU). 2. Assess the predictive value of USt for renal disease.

\section{METHODS}

Retrospective analysis of clinical records of 347 cats and 421 dogs undergoing USt, external testing, and urine SG measurement at a charity hospital over 3 years. Results were analysed for correlation of results from USt with EU and predictive value of USt results for renal disease (IRIS guidelines).

\section{RESULTS}

For dogs and cats, USt showed good (USt within 20\% of EU) correlation with EU in 38 cases (5\%), fair (USt within $50 \%$ ) in $100(13 \%)$ and poor (USt within 50\%) in 630 (72\%). In cats, good correlation was present in 21 (6\%), fair in 18 (5\%), and poor in $308(89 \%)$. In dogs, good correlation was present in 17 (4\%), fair in 20 (5\%), and poor in 384 (91\%).

Cats with renal disease $(n=130)$ were identified by USt in 42 cases (32\%), and cats without renal disease $(n=217)$ were identified in 40 cases $(11 \%)$ giving a PPV of $19 \%$ and a NPV of $31 \%$. Dogs with renal disease $(n=157)$ were identified in 56 cases (35\%) and dogs without renal disease $(n=264)$ were identified in 33 cases $(13 \%)$, giving a PPV of $20 \%$ and an NPV of $25 \%$.

\section{STATEMENT (CONCLUSIONS)}

The use of urea strips in small animal practice and "minimum databases" is highly questionable as they show generally poor correlation with laboratory values, and have a low positive and negative predictive value for renal disease.

\section{The use of midazolam in combination with medetomidine for premedication in healthy dogs}

\section{Delphine Le Chevallier, Jo Murrel}

Bristol University, Bristol, United Kingdom

\section{OBJECTIVES}

To assess the sedative effects of intravenous (IV) midazolam and medetomidine in combination at different doses compared to medetomidine alone in healthy dogs for premedication.

\section{METHODS}

Forty client owned dogs presented for elective neutering were enrolled in a prospective randomized blinded study. Dogs were assigned to four groups: medetomidine $15 \mu \mathrm{g} / \mathrm{kg}$ (positive control group), medetomidine $10 \mu \mathrm{g} / \mathrm{kg}$ \& midazolam $0.2 \mathrm{mg} / \mathrm{kg}$, medetomidine $5 \mu \mathrm{g} / \mathrm{kg}$ \& midazolam $0.3 \mathrm{mg} / \mathrm{kg}$ and medetomidine $5 \mu \mathrm{g} / \mathrm{kg} \& \mathrm{mida}-$ zolam $0.2 \mathrm{mg} / \mathrm{kg}$. The same clinician assessed sedation after administration at $T+2.5$ minutes and $T+5$ minutes using a composite simple descriptive sedation scale between 0 and $15(0=$ no sedation; $15=$ profound sedation). The dose of propofol for induction, quality of induction, ease of intubation and any adverse events were recorded.

\section{RESULTS}

There was no significant difference in sedation scores between treatment groups at $T+2.5$ minutes or $T+5$ minutes ( $p=0.82$ and $p=0.63$ respectively). Administration of midazolam in combination with medetomidine resulted in $71 \%$ of dogs displaying paradoxical behaviours $(p<0.0001)$ such as agitation, excitation, restlessness, aggression and vocalization which was different from pre-sedation state. Propofol requirement was not different between groups. Induction and tracheal intubation quality was smooth in all groups.

\section{STATEMENT (CONCLUSIONS)}

In healthy dogs, at the doses studied, the combination of midazolam-medetomidine administered IV for premedication provided moderate sedation but was associated with a high incidence of paradoxical behaviours. This drug combination IV is not recommended for premedication in dogs. 